\title{
Using high frequency oligonucleotides- targeting active gene (HFO-TAG) markers for genetic evaluation among genotypes (Cucurbita pepo L. and C. maxima L.)
}

\author{
Adel Ahmed Elshafei ${ }^{1 *}$ (D) Talal Khaled Alateeq ${ }^{2}$, Rafik Mostafa Habib ${ }^{3}$ and Mohamed Ibrahim Motawei ${ }^{4}$
}

\begin{abstract}
Background: Cucurbita spp. is a main source of crypto-xanthine, zeaxanthin lutein folates, and natural poly-phenolic flavonoid compounds. Collection and conservation of genetic variability are helpful in genetic advancement programs. Twenty-two pumpkin genotypes (21 genotypes of Cucurbita pepo L. and one genotype of C. maxima L.) were collected from different regions of Saudi Arabia. Fifteen HFO-TAGhigh frequency oligonucleotide-targeting active gene markers were used to analyze genetic variability among 22 pumpkin genotypes.

Results: A total of 107 alleles were detected by the 15 HFO-TAG markers, an average of 7.133 alleles per primer. Polymorphisms were found in 102 alleles, an average of 6.866 alleles per primer. The PIC values measured from all of the HFO-TAG markers were high, and ranged from 0.8940 to 0.7225 , with an average 0.8212 per marker.

Conclusions: The results of the cluster analysis of pumpkin genotypes were separated into seven groups according to the collection region.
\end{abstract}

Keywords: Pumpkin, Cucurbita pepo, Genetic diversity, HFO-TAG

\section{Background}

Five types of pumpkins are cultivated in Cucurbita (Cucurbita pepo, Cucurbita moschata, Cucurbita maxima, Cucurbita mixta, and Cucurbita ficifolia) (Naik et al. 2015). Cucurbita pepo L. is the generality economically essential species of (Cucurbitaceae). Cucurbita spp. are the main sources of crypto-xanthine, zeaxanthin lutein folates, and natural poly-phenolic flavonoid compounds including beta-carotenes, niacin, and vitamin B6. Cucurbita spp. exhibit anti-carcinogenic and antidiabetic properties, and an antioxidant effect (Yadav et al. 2010), and contain phosphorus, magnesium, and zinc (Mansour et al. 1993). Seeds also contain unsaturated fatty acids (of dietary importance for a healthy heart) and high concentrations of calcium, iron, potassium, beta-carotene, and simple proteins.

\footnotetext{
* Correspondence: elshafei_2000@yahoo.com

${ }^{1}$ Genetics and Cytology Department, Genetic Engineering and Biotechnology Division, National Research Centre (NRC), El-Dokki, Cairo, Egypt Full list of author information is available at the end of the article
}

Collection and conservation of genetic variability are helpful in genetic advancement programs. Genetic markers based on DNA such as random amplified polymorphic DNA (RAPD) were applied to examine the genetic difference in C. moschata in southern Africa and Korea (Youn and Chung, 1998; Gwanama et al. 2000; Baranek et al. 2000). As molecular marker technology improved, it became a helpful technique to determine genetic differences which are stabilized and not strongly influenced by environmental factors of the plant to develop vegetable breeding programs (Paris et al. 2003; Wu et al. 2011; Gong et al. 2012; Kong et al. 2014).

Presently, the use of molecular markers in genetic studies provides useful information for numerous biological aspects of genetic studies, including evolutionary aspects and relationships among organisms. The amplified fragment length polymorphism (AFLP) markers appear to be a helpful method to provide insights into the genetic diversity between landraces. These markers have been widely used for a quick study of genomic 
polymorphism, generate a number of reproducible experimental bands, and no previous data of the genome is required for their application (Vos et al. 1995; Montalvo Fernández et al. 2012). In addition, they have been used for phylogenetic and taxonomic studies and construction of interspecific maps with a great level of similarity with other molecular markers such as RFLP (restriction fragment length polymorphism), SSR (simple sequence repeat), RAPD, ISSR (inter simple sequence repeats), TRAP (target region amplification polymorphism), AFLP, and SRAP (sequence-related amplified polymorphic) (Florido et al. 2007).

In a recent study (Levi et al. 2010), the use of a new type of polymerase chain reaction (PCR) marker produced primers (high-frequency oligonucleotides-targeting active gene; HFO-TAG) representing oligonucleotides that exist in high frequency in the expressed sequence tag (EST) unigene of the watermelon fruit (Levi et al. 2006; Wechter et al. 2008). These markers proved to be very useful and reproducible in the genetic mapping of watermelon (Levi et al. 2010). The ability to amplify fragments from a cDNA library representing watermelon fruit to substantiate the possibility that the HFO-TAG primers were better suited than ISSR or RAPD primers to target active gene sequences was examined.

The HFO-TAG detected a broad genetic difference between Citrullus spp. and helped in determining the genetic variability of F1 hybrid rootstock lines for grafting Citrullus spp. (Levi et al. 2013). Miladinović et al. (2016) reported that the HFO-TAG primers are more efficient than ISSR or RAPD primers in targeting active gene loci. In the current study, we used HFO-TAG markers to examine genetic variability among 21 Cucurbita pepo L. genotypes and one C. maxima L. genotype that were collected from different locations in some regions of Saudi Arabia.

\section{Methods}

\section{Plant material}

Twenty-two pumpkin genotypes (21 Cucurbita pepo L. and one C. maxima L.) were collected from different regions of Saudi Arabia. These germplasms were collected for the Vegetable Breeding and Improvement Program at the Plant Production Department, College of Food and Agricultural Sciences, King Saud University, Saudi Arabia (Table 1).

Table 1 Genotype cod, English Name, Sc. name, and country of origin of 21 genotypes of Cucurbita pepo L. and one Cucurbita moschata L.

\begin{tabular}{|c|c|c|c|c|}
\hline Genotype cod & English name & Sc. name & Origin & Place of Coll. \\
\hline 1063 & Pumpkin & Cucurbita maxima L. & Unknown & Hail \\
\hline 972 & Pumpkin & Cucurbita pepo L. & Unknown & Buraidah \\
\hline 26 & Pumpkin & Cucurbita pepo L & Unknown & Unaizah \\
\hline 668 & Pumpkin sweet & Cucurbita pepo L. & E. Province & Al-Qateef \\
\hline 549 & Pumpkin & Cucurbita pepo L. & North & Hail \\
\hline 379 & Pumpkin & Cucurbita pepo L. & North & Rafha \\
\hline 24 & Pumpkin & Cucurbita pepo L. & Unknown & Al-Zulfi \\
\hline 208 & Pumpkin & Cucurbita pepo L. & Unknown & Riyadh \\
\hline 207 & Pumpkin & Cucurbita pepo L. & Unknown & Riyadh \\
\hline 235 & Pumpkin & Cucurbita pepo L. & Al-Jauf & Al-Jauf \\
\hline 481 & Pumpkin & Cucurbita pepo L. & Al-Qaseem & Buraidah \\
\hline 206 & Pumpkin & Cucurbita pepo L. & Unknown & Riyadh \\
\hline 27 & Pumpkin & Cucurbita pepo L. & Unknown & Al-Zulfi \\
\hline 97 & Pumpkin & Cucurbita pepo L. & Unknown & Al-Qateef \\
\hline 310 & Pumpkin & Cucurbita pepo L. & E. Province & Al-Ahsa \\
\hline 710 & Pumpkin & Cucurbita pepo L. & Al-Baha & Al-Muqwa Al-Ahsaba \\
\hline 870 & Pumpkin & Cucurbita pepo L. & E. Province & Al-Qateef \\
\hline 220 & Pumpkin & Cucurbita pepo L. & Al-Jauf & Al-Jauf \\
\hline 187 & Pumpkin & Cucurbita pepo L & Unknown & Al-Kharj \\
\hline 709 & Pumpkin & Cucurbita pepo L & Al-Baha & JabalShada \\
\hline 578 & Pumpkin & Cucurbita pepo L. & Tabuk & Taima \\
\hline 580 & Pumpkin & Cucurbita pepo L. & Unknown & Taima \\
\hline
\end{tabular}


Isolation of DNA

A Wizard Genomic DNA purification Kit (Promega Corporation Biotechnology, Madison, WI, USA) was used for extracting DNA from the leaves of all pumpkin genotypes. The extracted DNA was treated with RNase and stored in a refrigerator at $-20{ }^{\circ} \mathrm{C}$. The DNA quality was assessed using $0.8 \%$ agarose gel and an Epoch Multi-Volume Spectrophotometer (Biotek, Winooski, VT, USA). Before conducting the HFOTAG analysis, the DNA was diluted to a concentration of $25 \mathrm{ng} / \mu \mathrm{L}$.

\section{PCR amplification and analysis using HFO-TAG markers}

Fifteen HFO-TAG markers (Table 2) were used as defined by Levi et al. (2010). The PCR mixture $(25 \mu \mathrm{l})$ comprised 20 to $50 \mathrm{ng}$ of genomic DNA, $1 \times$ PCR buffer, $1.5 \mathrm{mM} \mathrm{MgCl}_{2}, 0.1 \mathrm{mM}$ dNTP, $0.5 \mu \mathrm{M}$ of primers, and $1 \mathrm{U}$ Taq polymerase. A PTC-200 thermocycler (MJ Research, Watertown, MA, USA) was used for the HFO-TAG primers amplifications, which were run for 40 cycles of $60 \mathrm{~s}$ at $94{ }^{\circ} \mathrm{C}$ to denature the DNA, and $70 \mathrm{~s}$ for primer annealing at 45 and 48 ${ }^{\circ} \mathrm{C}$ (as specified for each primer in Table 2). The amplified PCR products were applied to $3 \%(\mathrm{~m} / \mathrm{v})$ agarose gel containing $0.1 \mu \mathrm{g} \mathrm{cm}^{-3}$ ethidium in TBE buffer. After electrophoresis, a UV trans-illuminator was used to take a photograph of the gel. After excluding unreproducible bands, the HFO-TAG data were analyzed based on the presence (1) or absence (0) of a given marker.

\section{Molecular marker data and genetic variability}

A similarity matrix was estimated using HFO-TAG data according to Nei and Li, (1979):

$$
\mathrm{SM}=2 N_{i j} /\left(N_{i}+N_{j}\right)
$$

where,

$N_{i j}$ is the number of bands present in both the ith and jth genotypes,

$N_{i}$ is the number of bands present in the ith genotype, and

$N_{j}$ is the number of bands present in the $j t h$ genotype.

The similarity matrix was analyzed by the unweighted pair group method with the arithmetic average (UPGMA) clustering algorithm. A principal coordinate analysis (PCoA) was used as an alternative to hierarchical clustering where the similarity matrix was used to obtain the coordinates. These coordinates were then used to create scatter plots to represent the relationships among genotypes. Both UPGMA and PCoA were conducted using PAST version 1.62 (Hammer et al. 2001). The reliability of the generated dendrogram was evaluated using 1000 simulations with PAUP version 4.0b10 (Swofford, 2001). The polymorphic information content (PIC) was calculated according to Smith et al. (2000) as follows:

Table 2 The fifteen HFO-TAG markers that were tested in pumpkin genotypes

\begin{tabular}{|c|c|c|c|c|c|c|c|}
\hline Primer & Oligos & $\operatorname{Tm}(C)$ & $\mathrm{Ta}(\mathrm{C})$ & TF (no.) & PF (no.) & Fragment sizes & $\mathrm{PIC}$ \\
\hline HFO-4 & GGCGGCGG & 41.9 & 41 & 11 & 10 & $155,190,240,295,360,395,430,510,620,710,800$ & 0.8878 \\
\hline HFO-7 & GCCGCCGC & 43.5 & 50 & 8 & 7 & $190,310,390,470,530,600,685,720$ & 0.8364 \\
\hline HFO-8 & GCGGCGGC & 43.5 & 50 & 11 & 10 & $165,195,270,340,450,490,560,600,740,800,845$ & 0.8844 \\
\hline HFO-13 & TCCGCCGC & 38.4 & 45 & 4 & 4 & $200,310,500,565$ & 0.7474 \\
\hline HFO-14 & GCGGCGGA & 38.4 & 45 & 6 & 6 & $187,275,410,490,540,645$ & 0.7788 \\
\hline HFO-49 & GCGGCGGT & 39.1 & 45 & 7 & 7 & $309,445,725,810,840,875,900$ & 0.8306 \\
\hline HFO-50 & ACCGCCGC & 39.1 & 45 & 7 & 7 & $310,405,530,580,630,650,740$ & 0.8358 \\
\hline HFO-51 & TCGCCGCCG & 46.1 & 50 & 6 & 5 & $185,220,290,350,440,520$ & 0.7225 \\
\hline HFO-63 & GCCGGCGA & 38.4 & 45 & 5 & 5 & $435,540,600,680,800$ & 0.7721 \\
\hline HFO-67 & GCCGCTGC & 36.8 & 45 & 4 & 4 & $250,310,480,530$ & 0.8614 \\
\hline HFO-68 & GCAGCGGC & 36.8 & 45 & 8 & 8 & $350,420,570,680,720,800,840,900$ & 0.8575 \\
\hline HFO-71 & CCACCGCCG & 42.4 & 45 & 8 & 8 & $420,500,570,630,680,710,800,900$ & 0.8403 \\
\hline HFO-72 & CGGCGGTGG & 42.4 & 45 & 11 & 11 & $180,235,320,550,640,690,740,780,800,910,980$ & 0.8940 \\
\hline HFO-76 & GCCGGCGG & 41.9 & 45 & 7 & 7 & $200,300,365,430,560,675,710$ & 0.8453 \\
\hline HFO-77 & CCTCCGCCG & 41.2 & 45 & 4 & 4 & $200,235,450,675$ & 0.7239 \\
\hline Total & - & - & - & 107 & 103 & & 12.3182 \\
\hline Maxi. & & & & 11 & 11 & & 0.8940 \\
\hline Min. & & & & 4 & 4 & & 0.7225 \\
\hline Mean & - & - & - & 7133 & 6.866 & & 0.8212 \\
\hline
\end{tabular}




$$
P I C=1-\Sigma f i 2
$$

where, fi is the frequency of the ith allele in the set of genotypes.

\section{Results}

Analysis of polymorphism of HFO-TAG markers

Only 15 of 20 HFO-TAG markers were amplified among the 22 pumpkin genotypes. A total of 107 alleles were detected by the 15 HFO-TAG markers, an average of 7.133 alleles per primer. Polymorphisms were found in 102 alleles, an average of 6.866 alleles per primer (Table 2 ). The alleles amplified by the various primers were diverse (Fig. 1). The PIC rate measured from all the HFOTAG markers was high, and ranged from 0.894 to 0.722 , with a mean of 0.821 per marker. These results indicate a high genetic diversity among genotypes. The number of amplified alleles per primer were positively correlated $(r=0.763)$, with the PIC values (Table 2).

\section{Cluster analysis based on HFO-TAG markers}

Twenty-two pumpkin genotypes with 15 HFO-TAG markers were used for the evaluation of genetic diversity. Amplification polymorphism was found among the 22 pumpkin genotypes. A cluster analysis was performed using the similarity coefficients of the 107 scored alleles obtained from the HFO-TAG data (Table 2) and the 22 pumpkin genotypes were grouped into seven groups with similarity coefficients between 0.11 and 0.80 . The maximum genetic similarity was found between genotypes 26 and 481 (0.80), which were collected from same the region of Al-Qaseem (Unaizah and Buraidah). The lowest similarity (0.11) was between three genotypes from the same region (Al-Qateef; genotypes 97, 688, and 870 ) and genotype 310 from the Al-Ahsa region (Table 3 and Fig. 1).

The seven groups were defined using bootstrap values. The first group with a bootstrap value of $44 \%$ comprised five genotypes containing two subgroups. The first subgroup had a bootstrap value of $41 \%$ and comprised one genotype (310), which was collected from the Al-Ahsa region. The second subgroup with a bootstrap value of $58 \%$ comprised four genotypes (206, 207, and 208 from the Riyadh region and 187 from the Al-Kharj region). The second group had a

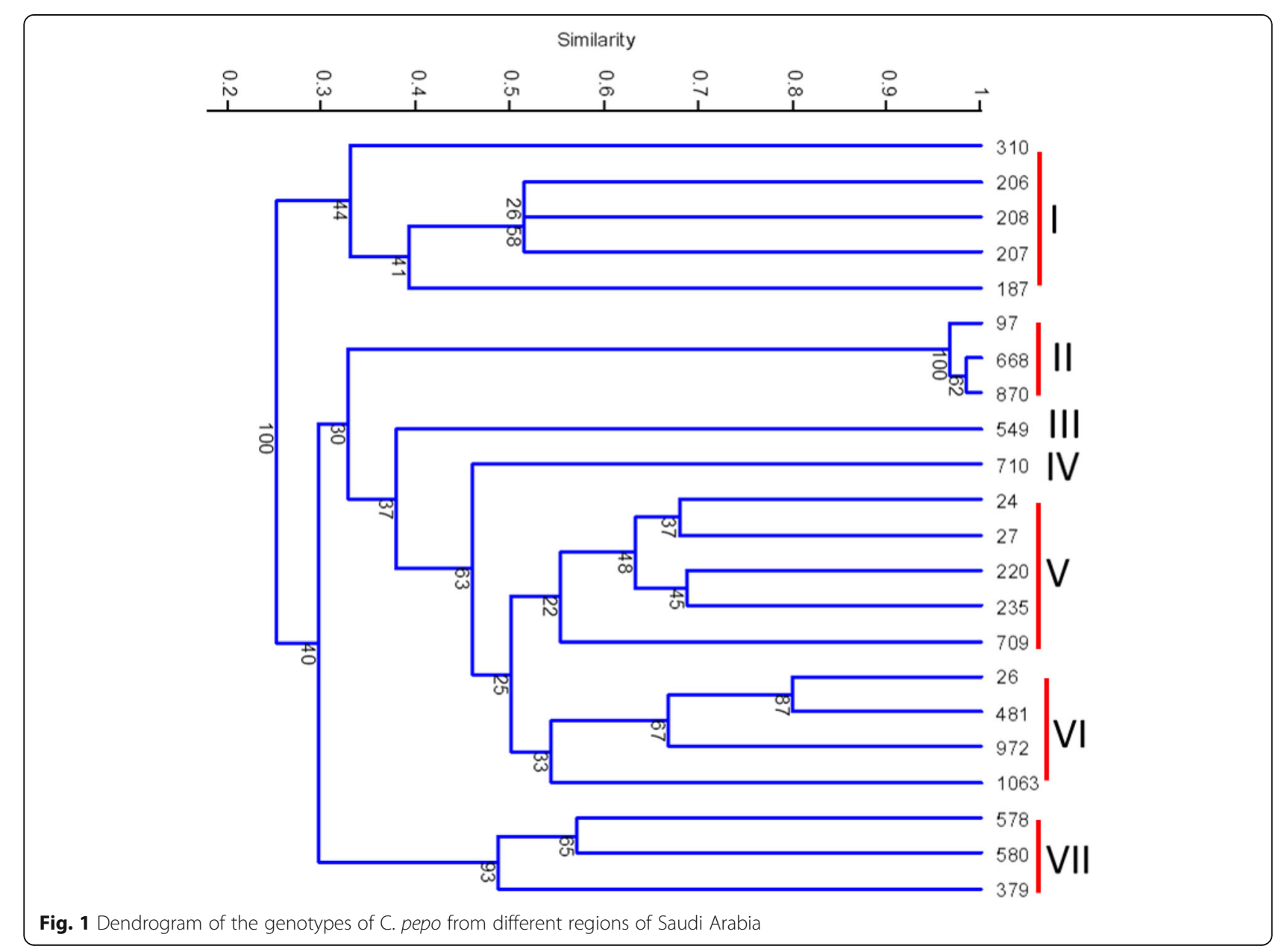


Table 3 Binary matrix and similarity indices among pumpkin genotypes

\begin{tabular}{|c|c|c|c|c|c|c|c|c|c|c|c|c|c|c|c|c|c|c|c|c|c|c|}
\hline & 1063 & 26 & 481 & 792 & 24 & 27 & 220 & 235 & 709 & 710 & 578 & 580 & 379 & 97 & 688 & 870 & 310 & 206 & 207 & 208 & 549 & 187 \\
\hline 1063 & 1 & & & & & & & & & & & & & & & & & & & & & \\
\hline 26 & 0.58 & 1.00 & & & & & & & & & & & & & & & & & & & & \\
\hline 481 & 0.56 & 0.80 & 1.00 & & & & & & & & & & & & & & & & & & & \\
\hline 792 & 0.49 & 0.64 & 0.70 & 1.00 & & & & & & & & & & & & & & & & & & \\
\hline 24 & 0.45 & 0.52 & 0.57 & 0.62 & 1.00 & & & & & & & & & & & & & & & & & \\
\hline 27 & 0.49 & 0.53 & 0.55 & 0.61 & 0.68 & 1.00 & & & & & & & & & & & & & & & & \\
\hline 220 & 0.38 & 0.41 & 0.42 & 0.49 & 0.59 & 0.58 & 1.00 & & & & & & & & & & & & & & & \\
\hline 235 & 0.39 & 0.48 & 0.50 & 0.53 & 0.68 & 0.67 & 0.69 & 1.00 & & & & & & & & & & & & & & \\
\hline 709 & 0.47 & 0.55 & 0.57 & 0.50 & 0.55 & 0.59 & 0.48 & 0.60 & 1.00 & & & & & & & & & & & & & \\
\hline 710 & 0.36 & 0.46 & 0.42 & 0.43 & 0.47 & 0.48 & 0.42 & 0.55 & 0.55 & 1.00 & & & & & & & & & & & & \\
\hline 578 & 0.25 & 0.33 & 0.31 & 0.30 & 0.31 & 0.30 & 0.47 & 0.32 & 0.32 & 0.38 & 1.00 & & & & & & & & & & & \\
\hline 580 & 0.26 & 0.32 & 0.32 & 0.31 & 0.30 & 0.27 & 0.35 & 0.27 & 0.29 & 0.26 & 0.57 & 1.00 & & & & & & & & & & \\
\hline 379 & 0.17 & 0.30 & 0.27 & 0.25 & 0.24 & 0.23 & 0.30 & 0.31 & 0.22 & 0.24 & 0.44 & 0.54 & 1.00 & & & & & & & & & \\
\hline 97 & 0.24 & 0.24 & 0.25 & 0.32 & 0.38 & 0.32 & 0.49 & 0.36 & 0.29 & 0.32 & 0.35 & 0.34 & 0.27 & 1.00 & & & & & & & & \\
\hline 688 & 0.23 & 0.25 & 0.26 & 0.34 & 0.38 & 0.34 & 0.51 & 0.38 & 0.30 & 0.32 & 0.36 & 0.34 & 0.27 & 0.98 & 1.00 & & & & & & & \\
\hline 870 & 0.22 & 0.25 & 0.26 & 0.33 & 0.38 & 0.33 & 0.50 & 0.37 & 0.30 & 0.31 & 0.35 & 0.34 & 0.26 & 0.96 & 0.98 & 1.00 & & & & & & \\
\hline 310 & 0.23 & 0.22 & 0.21 & 0.17 & 0.17 & 0.17 & 0.15 & 0.18 & 0.24 & 0.15 & 0.18 & 0.21 & 0.23 & 0.11 & 0.11 & 0.11 & 1.00 & & & & & \\
\hline 206 & 0.39 & 0.51 & 0.46 & 0.38 & 0.29 & 0.28 & 0.25 & 0.28 & 0.35 & 0.26 & 0.24 & 0.31 & 0.29 & 0.23 & 0.23 & 0.21 & 0.31 & 1.00 & & & & \\
\hline 207 & 0.27 & 0.28 & 0.30 & 0.28 & 0.27 & 0.19 & 0.20 & 0.25 & 0.30 & 0.20 & 0.20 & 0.25 & 0.22 & 0.23 & 0.23 & 0.21 & 0.31 & 0.51 & 1.00 & & & \\
\hline 208 & 0.38 & 0.44 & 0.46 & 0.38 & 0.33 & 0.32 & 0.26 & 0.31 & 0.41 & 0.28 & 0.30 & 0.33 & 0.31 & 0.19 & 0.20 & 0.18 & 0.34 & 0.51 & 0.51 & 1.00 & & \\
\hline 549 & 0.36 & 0.40 & 0.37 & 0.40 & 0.42 & 0.38 & 0.38 & 0.39 & 0.36 & 0.31 & 0.26 & 0.27 & 0.27 & 0.36 & 0.35 & 0.34 & 0.20 & 0.35 & 0.37 & 0.39 & 1.00 & \\
\hline 187 & 0.24 & 0.23 & 0.23 & 0.26 & 0.20 & 0.23 & 0.18 & 0.24 & 0.26 & 0.19 & 0.13 & 0.20 & 0.19 & 0.14 & 0.14 & 0.14 & 0.35 & 0.32 & 0.41 & 0.45 & 0.26 & 1.00 \\
\hline
\end{tabular}

bootstrap value of $100 \%$ and comprised three genotypes $(97,668$, and 870) which were collected from the same region (Al-Qateef). The third group had a bootstrap value of $37 \%$ and comprised one genotype (549) collected from the Hail region. The fourth group had a bootstrap value of $33 \%$ and comprised genotype 710 collected from the Al-Baha region.

The fifth group had a bootstrap value of $48 \%$ and included three subgroups. The first subgroup had a bootstrap rate of $37 \%$ and comprised two genotypes (24 and 27) collected from the same region (Al-Zulfi). A second subgroup with a bootstrap value of $45 \%$ comprised two genotypes (220 and 235) collected from the same region (Al-Jauf). A third subgroup with a bootstrap value of $22 \%$ comprised one genotype (709), collected from the Al-Baha region. The sixth group had a bootstrap value of $33 \%$ and comprised four genotypes $(26,481$, and 971 collected from the same region (Unaizah, Buraidah) and 1063 collected from the Hail region). The seventh group had a bootstrap value of $93 \%$ and comprised three genotypes (578, 580, and 379) collected from the north Saudi Arabia region (Rafha and Tabuk). In general, the 22 pumpkin genotypes were separated according to the collection regions.

\section{PCoA-based HFO-TAG markers}

The PCoA plotted the first three components, which explained $60.8 \%$ of the variance (Fig. 2). Accessions in the PCoA scatter plot formed close groupings. The groups were basically the same as the cluster analysis groups. The genotypes were clustered into seven groups depending on the collection region.

\section{Discussion}

Analysis of polymorphism of HFO-TAG markers

The HFO-TAG markers generated polymorphic fragments (mean of 1.77 polymorphic alleles per primer) that were better when compared with RAPD and ISSR primers (means of 0.47 and 0.89 alleles per primer, respectively) (Levi et al. 2010). Elshafei et al. (2011) using nine TRAP primers were found between 2 and 19 amplified alleles per primer. Additionally, a total of 65 alleles were generated by 19 SRAP markers of which $27.7 \%$ were not polymorphic. However, $72.3 \%$ were polymorphic within six Yucca spp. genotypes. A total of 65 alleles were found with 7.2 alleles per primer with 57 (87.7\%) of these bands being polymorphic (Elshafei et al. 2011). Solmaz et al. (2016) reported that the overall results displayed low genetic diversity within the Turkish watermelon genotypes in contrast with their high 


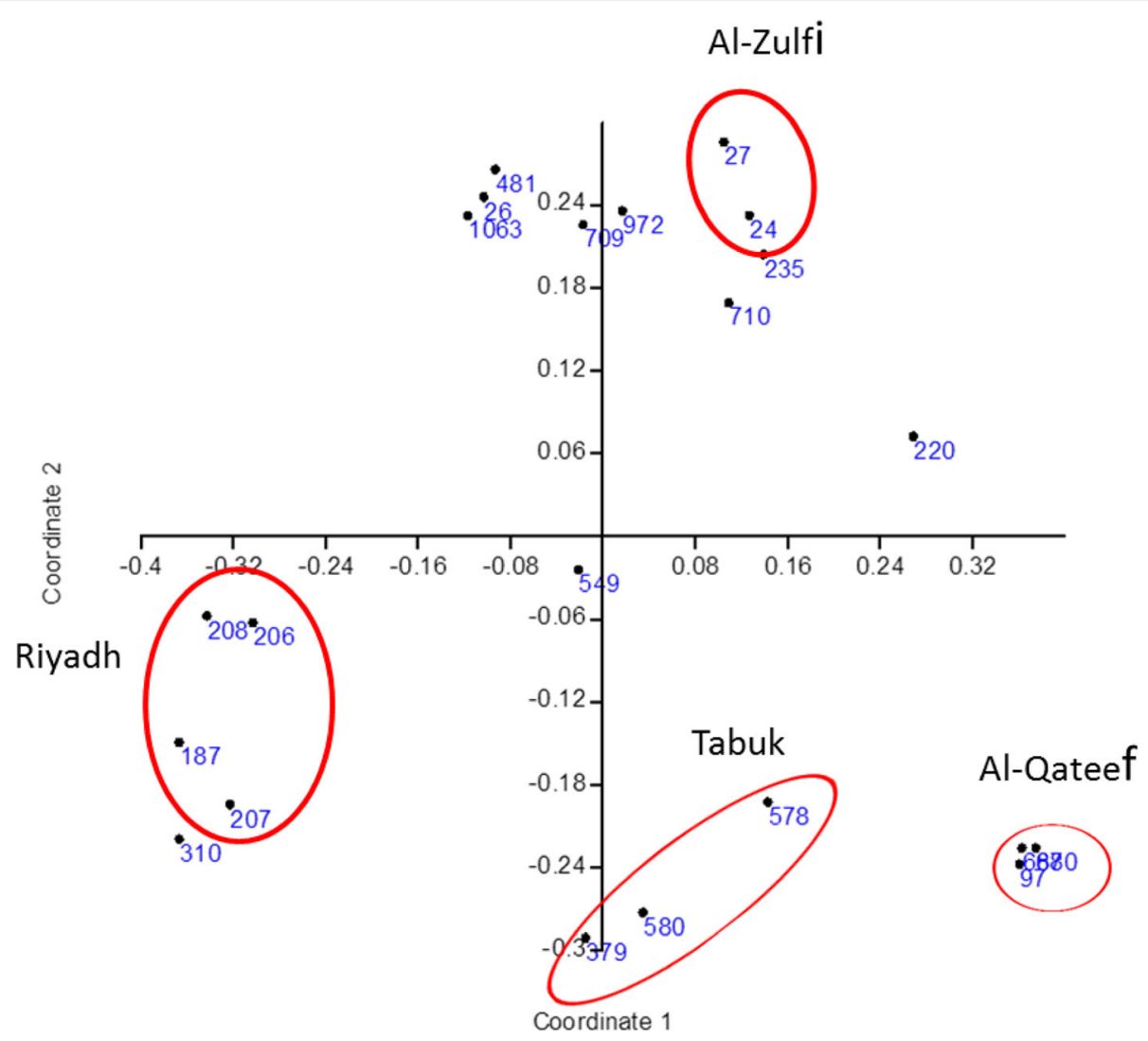

Fig. 2 PCoA of 22C. pepo with 15 HFO-TAG markers

morphological diversity. Using 23 SSR markers of 1197 watermelon landraces, the PIC value ranged from 0.35 to 0.70 , with an average of 0.49 (Zhang et al. 2016). ). Examining nineteen landraces of Cucurbita argyrosperma and 6 wild of sororia from Mexico, the levels of genetic diversity were similar for sororia and argyrosperma. Differentiation (FST) among populations within each subspecies ranged from 0.152 to 0.652 , and the cluster analysis for argyrosperma were three genetic groups (Yucatan Peninsula, Northern Mexico, including Michoacan and Veracruz, and Pacific coast plus Durango) Sánchez-de la Vega et al. (2018).

\section{Cluster analysis based on HFO-TAG markers}

The genetic similarity coefficients were estimated using the SSR and SRAP results. Cluster analysis and PCoA indicated that the germplasm of Citrullus lanatus var. lanatus collected from various areas of Turkey were closely related (Solmaz et al. 2016). Using 14 RAPD primers, a total of $44(84.1 \%)$ alleles were polymorphic among the pumpkin genotypes (Cucurbita pepo L.), (Méndez-López et al. 2018). In this study, in general, the 22 pumpkin genotypes were separated according to the collection regions. The same results were reported by Barboza et al. (2012) using 3 SSCP primers (ITS1-ITS2 and tRNL-F) with 218 lines of Cucurbita moschata Duchesne which were collected from Mexico and other countries in Central America. The results indicated a high level of genetic variation. It was found that the number of haplotypes was independent of the geographical source of the accession, and haplotypes were distributed randomly throughout the study area. Mexico had the highest values of total genetic variation while Panama showed the lowest values (Barboza et al. 2012).

The cluster analysis by AFLP exhibited an 89.4-99.4\% similarity in the genome of all tested Cucurbita spp. genotypes from diverse locations (Moya-Hernández et al. 2018). Elshafei et al. (2019b) found that genetic similarity among the faba bean genotypes ranged from 0.24 to 0.96 . The cluster analysis of faba bean genotypes resulted in five main clusters generally based on the origin and genetic background. The dendrogram of genetic similarity produced five groupings; the genetic distance was very close to one, with a range of 0.657 and 0.977 (Méndez-López et al. 2018). The genetic similarity among 15 rice genotypes ranged from 0.30 to 0.82 . The cluster analysis of 15 rice genotypes was generally based on pedigree (Elshafei et al. 2019a). The mean genetic distance values among Cucurbita species had a broad range, from 0.37 to 0.78 . The mean genetic distance 
values among accessions within the same species were markedly lower than among species (Gong et al. 2013). The sixteen genotypes of pumpkin of the two species (Cucurbita moschata and Cucurbita maxima) were collected from different localities from KSA. Similarity coefficient indicates between the studied genotypes of pumpkin in KSA ranged from 1.00 to 0.0 according to biochemical and molecular profiles. The cluster analysis of 16 pumpkin genotypes was separated into two groups. The first group includes Cucurbita maxima and the second group includes C. moschata, Abdein et al. (2018).

\section{PCoA-based HFO-TAG markers}

The PCoA analysis of the ITS1-ITS2 haplotypes explained $70.18 \%$ of the variability among accessions. The first PCoA demonstrated $30.04 \%$ of the variability, the second demonstrated $23.68 \%$ variability, and the third explained $16.46 \%$ of the observed variability. The dispersion of the genotypes indicated three groups. The first group comprised a large number of genotypes of C. moschata, mainly from El Salvador, Mexico, and Nicaragua. The second group mostly comprised genotypes from Guatemala, Honduras, and Costa Rica. The third group comprised genotypes from Guatemala, Mexico, and Panama (Barboza et al. 2012). The PCoA of Cucurbita accessions collected from different geographic origins belonged to nine species of pumpkin divided into clusters according to species (Gong et al. 2013).

In the PCoA analysis using nine RAPD primers with 15 rice genotypes, the first five principal coordinates accounted for $87.6 \%$ of the total variation. Accessions in the PCoA scatter plot appeared to form a very close grouping in the dendrogram (Elshafei et al. 2019a). The PCoA analysis of eight SRAP markers with 18 lines of faba bean, showed that the first three PCoA accounted for $63.8 \%$ of the total variation in accessions in the PCoA scatter plot, indicated by ellipses and numbered with $\mathrm{A}, \mathrm{B}, \mathrm{C}, \mathrm{D}$, and $\mathrm{E}$, forms a super closed group in the dendrogram (Elshafei et al. 2019b).

\section{Conclusion}

Successful breeding programs for any crop were to determine the degree of genetic variation for pumpkin genotypes. In this study, genetic differences have been identified for 22 genotypes of pumpkin ranging from 0.11 to 0.8 for genotypes were separated by analyzing cluster to 7 groups, according to geographic origins.

\footnotetext{
Abbreviations

AFLP: Amplified fragment length polymorphismESTExpressed sequence tagHFO-TAGHigh-frequency oligonucleotide-targeting active genePCoAPrincipal coordinate analysisPCRPolymerase chain reactionPICPolymorphic information contentRAPDRandom amplified polymorphic DNARFLPRestriction Fragment Length PolymorphismSRAPSequence-related amplified polymorphicSSCPSingle-strand conformation polymorphism analysisSSRSimple sequence repeatUPGMAUnweighted pair group method with arithmetic average
}

\section{Acknowledgements}

The authors would like to thank Prof. M. Motawei for the suggestions and proofreading this manuscript.

\section{Authors' contributions}

EAA performed the analysis with the molecular markers. MN, TKA, RMH DNA extraction and PCR amplification. MIM reviewed the research and responded to the comments of the reviewers. All authors read and approved the final manuscript.

\section{Funding}

This study was funded by the authors.

\section{Availability of data and materials}

The authors declare that the experimental data and material are available.

\section{Ethics approval and consent to participate}

The authors declare that the work is ethically approved and consent to participate.

\section{Consent for publication}

The authors declare that the work has been consented for publication.

\section{Competing interests}

The authors declare that they have no competing interests.

\section{Author details}

${ }^{1}$ Genetics and Cytology Department, Genetic Engineering and Biotechnology Division, National Research Centre (NRC), El-Dokki, Cairo, Egypt. ${ }^{2}$ Plant Production Department, College of Food and Agricultural Sciences, King Saud University, Riyadh, Saudi Arabia. ${ }^{3}$ Genetic Resources Department, Desert Research Center, El-Matareya, Cairo, Egypt. ${ }^{4}$ Crop Science Department, Faculty of Agriculture, Alexandria University, P.O. Box 21545, Alexandria, Egypt.

Received: 22 July 2019 Accepted: 15 October 2019

Published online: 29 November 2019

\section{References}

Abdein MAE (2018) Genetic diversity between pumpkin accessions growing in the northern border region in Saudi Arabia based on biochemical and molecular parameters Egypt. J. Bot 58:463-476

Baranek M, Stift G, Vollmann J, Lelley T (2000) Genetic diversity within and between the species Cucurbita pepo, C. moschata and C. maxima as revealed by RAPD markers. Cucurbit Genet Coop Rep 23:73-77

Barboza N, Albertazzi FJ, Sibaja-Cordero JA, Mora-Umaña F, Astorga C, Ramírez P (2012) Analysis of genetic diversity of Cucurbita moschata (D.) germplasm accessions from Mesoamerica revealed by PCR SSCP and chloroplast sequence data. Sci Horti 134:60-71

Elshafei A, Barakat M, Milad S, Khattab S, Al-mutlaq M (2019a) Regeneration of rice somaclons tolerant to high level of abscisic acid and their characterization via RAPD markers. Bulletin of the National Research Centre 43(1):107

Elshafei AA, Esmaiel NM, Al-Doss AA, Barakat MN (2011) An assessment of the cultural capabilities of clonal propagation and molecular characterization of Yucca elephantipes cultivars. J Med Plant Res 5(13):2896-2905

Elshafei AAM, Amer MAE, Elenany MAM, Helal AGE (2019b) Evaluation of the genetic variability of faba bean (Vicia faba L.) genotypes using agronomic traits and molecular markers. Bulletin of the National Research Centre 43(1): 106.

Florido M, Arencibia A, Plana D, Alvarez M, López J, Lara RM (2007) Análisis de la diversidad genética en tomate (Solanum L. sección Lycopersicon subsección Lycopersicon) utilizando AFLP. Cultivos Tropicales 28:83-87

Gong L, Paris HS, Nee MH, Stift G, Pachner M, Vollmann J, Lelley T (2012) Genetic relationships and evolution in Cucurbita pepo (pumpkin, squash, gourd) as revealed by simple sequence repeat polymorphisms. Theor Appl Genet. 124: 875-891

Gwanama C, Labuschagne MT, Botha AM (2000) Analysis of genetic variation in Cucurbita moschata by random amplified polymorphic DNA (RAPD) markers. Euphytica 113:19-24 
Hammer D, Harper A, Ryan P (2001) PAST: Palaeontological Statistics software package for education and data analysis. Palaeontol Electron 4(1):4-9

Kong Q, Chen J, Liu Y, Ma Y, Liu P, Wu S, Huang Y, Bie Z (2014) Genetic diversity of Cucurbita rootstock germplasm as assessed using simple sequence repeat markers. Sci Hortic 175:150-155

Levi A, Davis A, Hernandez A, Wechter P, Thimmapuram J, Trebitsh T, Tadmor Y, Katzir N, Portnoy V, King S (2006) Genes expressed during the development and ripening of watermelon fruit. Plant Cell Rep. 25:1233-1245 https://doi. org/10.1007/s00299-006-0163-0

Levi A, Thies JA, Wechter WP, Harrison HF, Simmons AM, Reddy UK, Fei Z (2013) High frequency oligonucleotides: Targeting active gene (HFO-TAG) markers revealed wide genetic diversity among Citrullus spp. accessions useful for enhancing disease or pest resistance in watermelon cultivars. Genet Resour Crop Evol 60(2):427-440 https://doi.org/10.1007/s10722-012-9845-3

Levi A, Wechter WP, Harris-Shultz KR, Davis AR, Fie Z (2010) High-frequency oligonucleotides in watermelon expressed sequenced tag-unigenes are useful in producing polymorphic polymerase chain reaction markers among watermelon genotypes. J Amer Hort Sci. 135:369-378

Mansour EH, Dworschák E, Lugasi A, Barna É, Gergely A (1993) Nutritive value of pumpkin (Cucurbita Pepo) seed products. J Sci Food Agric 61(1):73-78

Méndez-López A, Sánchez-Vega M, Villanueva-Verduzco C, Rojas-Martínez RI, Rodríguez-Pagaza Y (2018) Genetic diversity in parthenocarpic varieties of pumpkin (Cucurbita pepo L.) BY RAPD. Trop Subtrop Agroecosyst 21(3):447-455

Miladinović D, Dimitrijević A, Brdar-Jokanović M, Imerovski I, Sikora V, Marjanović Jeromela A, Jocić S (2016) Molecular analysis of NS Cucurbita moschata collection. Proceedings of the III International Congress "Food Technology, Quality and Safety", Novi Sad, 25-27th October 2016, p. 6-9

Montalvo-Fernández G, Quiroz Moreno A, Rojas Jiménez L, Quiala Mendoza E, Mederos-Oroza R, Morffi-Mestre H, Sánchez-Teyer LF (2012) Primer reporte de empleo de marcadores AFLP en Asteraceaeen Cuba. Rev Colomb Biotecnol. XIV, 28-37.

Moya-Hernández A, Bosquez-Molina E, Serrato-Díaz A, Blancas-Flores G, AlarcónAguilar FJ (2018) Analysis of genetic diversity of Cucurbita ficifolia Bouché from different regions of Mexico, using AFLP markers and study of its hypoglycemic effect in mice. South Afr J Bot 116:110-115 https://doi.org/10. 1016/j.sajb.2018.02.409

Naik ML, Prasad VM, Rajya LP (2015) A study on character association and path analysis in pumpkin (Cucurbita moschata Duch. ex Poir.). Int J Adv Res 3: 1030-1034

Nei M, Li WH (1979) Mathematical model for studying genetic variation in terms of restriction endonucleases. Proc Natl Acad Sci 76(10):5269-5273

Paris HS, Yonash N, Mozes-Daube VPN, Tzuri G, Katzir N (2003) Assessment of genetic relationships in Cucurbita pepo (Cucurbitaceae) using DNA markers. Theor Appl Genet 106:971-978

Sánchez-de la Vega G, Castellanos-Morales G, Gámez N, Hernández-Rosales HS, Vázquez-Lobo A, Aguirre-Planter E, Eguiarte LE (2018) Genetic Resources in the "Calabaza Pipiana" Squash (Cucurbita argyrosperma) in Mexico: Genetic Diversity, Genetic Differentiation and Distribution Models. Front Plant Sci 9: 400. https://doi.org/10.3389/fpls.2018.00400

Smith JSC, Kresovich S, Hopkins MS, Mitchell SE, Dean RE, Woodman WL, Lee M, Porter M (2000) Genetic diversity among elite sorghum inbred lines assessed with simple sequence repeats. Crop Sci 40(1):226-232

Solmaz I, Aka-Kaçar Y, Sari N, Şimşek Ö (2016) Genetic diversity within Turkish watermelon [Citrulluslanatus (Thunb.) Matsumura \&Nakai] accessions revealed by SSR and SRAP markers. Turk J Agric For 40:407-419 https://doi.org/10. 3906/tar-1511-26

Swofford DL (2001) PAUP: Phylogenetic Analysis Using Parsimony (and other methods) 4.0.b5

Vos P, Hogers R, Bleeker M, Reijans M, van de Lee T, Hornes M, Frijters A, Pot J, Peleman J, Kuiper M, Zabeau M (1995) AFLP: a new technique for DNA fingerprinting. Nucleic Acids Res 23:4407-4414 https://doi.org/10.1093/nar/ 23.21.4407

Wechter WP, Levi A, Harris KR, Davis AR, Fei ZJ, Katzir N, Giovannoni JJ, Salman A, Hernandez A, Thimmapuram J, Tadmor V, Portnoy V, Trebitsh T (2008) Gene expression in developing watermelon fruit. BMC-Genom 9:275-282

Wu J, Chang Z, Wu Q, Zhan H, Xie S (2011) Molecular diversity of Chinese Cucurbita moschata germplasm collections detected by AFLP markers. Sci Hortic 128:7-13
Yadav M, Jain S, Tomar R, Prasad GB, Yadav H (2010) Medicinal and biologica potential of pumpkin: An Updated Review. Nutri Res Rev 23(2):184-190 https://doi.org/10.1017/S0954422410000107

Youn SJ, Chung HD (1998) Genetic relationship among the local varieties of Korean native squashes (Cucurbita moschata) using RAPD technique. J. Korean Soc. Hortic Sci. 39:517-521 (In Korean, with English abstract).

Zhang H, Fan J, Guo S, Ren Y, Gong G, Zhang J, Xu Y (2016) Genetic diversity, population structure, and formation of a core collection of 1197 Citrullus accessions. Hort Sci. 51(1):23-29

\section{Publisher's Note}

Springer Nature remains neutral with regard to jurisdictional claims in published maps and institutional affiliations.

\section{Submit your manuscript to a SpringerOpen ${ }^{\circ}$ journal and benefit from:}

- Convenient online submission

Rigorous peer review

- Open access: articles freely available online

High visibility within the field

- Retaining the copyright to your article

Submit your next manuscript at $\boldsymbol{\nabla}$ springeropen.com 